\title{
Inhibition of miR-183 Induces Insulin in Dental Pulp Cells
}

\author{
Tadashige Nozaki ${ }^{1)}$ and Kiyoshi Ohura ${ }^{1)}$ \\ ${ }^{1)}$ Department of Pharmacology, Faculty of Dentistry, Osaka Dental University, Osaka, Japan \\ (Accepted for publication, July 14, 2017)

\begin{abstract}
We previously reported that miR-183 was downregulated during the direct conversion of dental pulp cells to insulin-producing cells. To further elucidate the role of miRNA regulation in dental pulp cells during this process, we examined the effect of $m i R-183$ inhibition. Insulin expression was detected in induced cells 72 hours after ectopic expression of $m i R-183$ inhibitor. The expression levels of insulin 1 and insulin 2 mRNA increased 1.7-fold and 1.6-fold, respectively. Insulin copy number estimates, following miR-183 inhibition, showed more than 10 copies each of insulin 1
\end{abstract} \\ and insulin 2. These data suggest that miR-183 downregulation induces the direct conversion of dental pulp cells to insulin- \\ producing cells.
}

Key words: Dental pulp, Differentiation, Direct reprogramming, Gene expression, miR-183

\section{Introduction}

Dental pulp-derived cells can differentiate into osteogenic, neurogenic, myogenic, and adipogenic lineage cells by applying in vitro induction conditions similar to those used for human bone marrow cells ${ }^{1-5)}$. Notably, demethylation by 5 -azacytidine triggers myogenic differentiation, suggesting that epigenetic modification is involved in lineage differentiation in dental pulp cells ${ }^{5}$. Several pluripotent stem cell markers have been identified, including Nanog, Sox2, and Oct3/4 (also known as Pou $5 f 1)^{6,7)}$. Induced pluripotent stem (iPS) cells are produced by transfecting four genes, including Sox 2 and Oct $3 / 4$, into fibroblasts $^{8}$. Stem cell markers such as STRO-1, SSEA-1, Nanog, and Oct3/4 are expressed at low levels in dental pulp-derived cells, and downregulation of these markers is observed during lineage differentiation ${ }^{1)}$.

Previously, we reported that dental pulp cells can be directly converted to insulin-producing cells $s^{9}$. In vitro induction was performed using conditions similar to those reported for the differentiation of undifferentiated intestinal cells into endocrine progenitor cells ${ }^{10-12)}$. Following the ectopic expression of defined transcription factors, the direct conversion of cells to endocrine lineage cells was induced, and insulin-producing cells were detected. Using microRNA array profiling, some miRNAs were found to have significantly different expression patterns after 10 days of induction ${ }^{9}$. Notably, after induction, cellular miR- 183 levels decreased by approximately $60 \%$. To further elucidate the role of $m i R-183$ in the direct conversion of dental pulp cells into insulin-producing cells, miR-183 was inhibited, and the extent of miRNA regulation evaluated.

\section{Cell culture}

\section{Materials and Methods}

Five-week old male Wistar rats were used in this study (Shimizu Laboratory Supply Co, Kyoto, Japan). Primary cultures were performed as previously described ${ }^{4}$. Briefly, approaching from the central side of the mandible, incisor dental pulp tissue was gently separated away

Correspondence to: Dr Tadashige Nozaki, Department of Pharmacology, Faculty of Dentistry, Osaka Dental University, 8-1 Kuzuhahanazono-cho, Hirakata, Osaka, 5731121 Japan; Tel: +81-72-864-3058; Fax: +81-72-864-3158; E-mail: nozaki@cc.osakadent.ac.jp from the distal site of the molars to excise the apical bud, using reamers (25 mm \#10; Morita Co, Osaka, Japan). The tissue was then minced and incubated in phosphate-buffered saline (PBS) containing $3 \mathrm{mg} /$ $\mathrm{ml}$ type I collagenase (Invitrogen, Carlsbad, CA, USA) and $4 \mathrm{mg} / \mathrm{ml}$ dispase (Invitrogen) for $50 \mathrm{~min}$ at $37^{\circ} \mathrm{C}$. The cells were cultured in MFstart basic medium (Toyobo Co, Osaka, Japan) supplemented with $10 \%$ $(\mathrm{v} / \mathrm{v})$ fetal calf serum (Invitrogen) at $37^{\circ} \mathrm{C}$ in a humidified atmosphere containing $5 \% \mathrm{CO}_{2}$. Animal experiments were performed in accordance with the Osaka Dental University guidelines for the care and use of laboratory animals.

\section{Induction assay}

Ambion anti-miR miRNA inhibitors (Thermo Fisher Scientific, Waltham, MA, USA) are chemically modified, single stranded nucleic acids designed to specifically bind to and inhibit endogenous miRNA molecules. Anti-miR miRNA inhibitors enable functional miRNA analysis by downregulating miRNA activity. miR-183 inhibitor $(50 \mathrm{nM})$ was transfected into the cells 2 days after inoculation. A mock study was also performed using $50 \mathrm{nM} \mathrm{Cy} 3$ dye-labeled antimiR negative controls (Thermo Fisher Scientific, Tokyo, Japan). Transfections were performed using the FuGENE HD transfection reagent (Roche Diagnostics, Indianapolis, IN, USA) in accordance with the manufacturer's instructions. The medium was replaced with basic medium 1 day after each transfection. Subsequently, the expression of markers was examined to evaluate the effects of differentiation in the cells.

\section{Immunostaining}

After fixation with $4 \%(\mathrm{w} / \mathrm{v})$ paraformaldehyde, cells were treated with $0.1 \mathrm{M}$ phosphate buffer containing $0.1 \%$ Triton X-100, washed with $10 \mathrm{mM}$ glycine in PBS and incubated in $3 \%(\mathrm{w} / \mathrm{v})$ BSA in PBS for 30 minutes at room temperature $\left(20-25^{\circ} \mathrm{C}\right)$ to block nonspecific reactions. After washing with $10 \mathrm{mM}$ glycine in PBS, the cells were incubated with an appropriately diluted primary antibody for 1 hour at room temperature, washed with $0.1 \%$ BSA in PBS, and incubated for 1 hour at room temperature with a fluorescently labeled secondary antibody. An anti-Insulin guinea pig antibody (1:200; Abcam, Cambridge, UK) was used as the primary antibody, and Alexa 

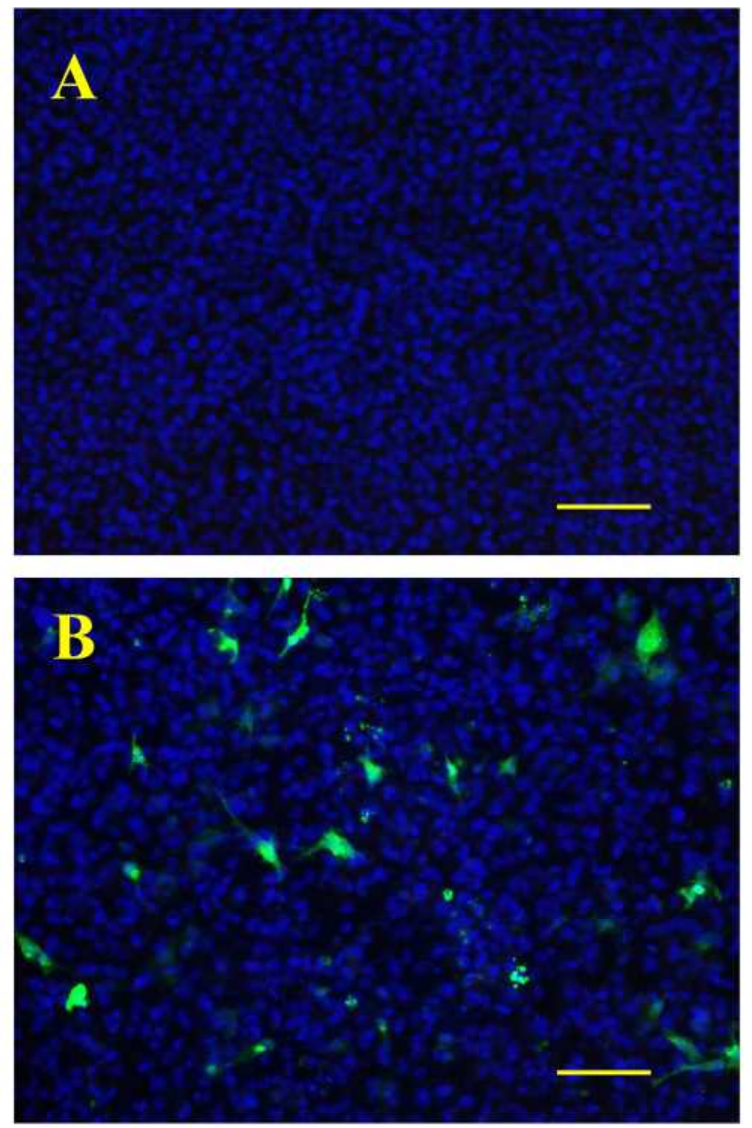

Figure 1. Expression of insulin in dental pulp cells by inhibition of miR-183

Panels showing anti-insulin antibody staining (green signals represent insulin production) of dental pulp cells after mock (Cy3 anti-miR negative controls) (A) and $m i R-183$ inhibitor (B) transfection. Scale bars indicate $100 \mu \mathrm{m}$.

488-conjugated goat anti-guinea pig (1:1000; Molecular Probes, Eugene, Oregon, USA) was used as the secondary antibody. The samples were then washed with $0.1 \%$ BSA in PBS, counterstained with 4', 6-diamidino-2-phenylindole (Invitrogen) and mounted in Permafluor (Immunotech, Marseille, France). Immunofluorescence signals were observed by fluorescence microscopy, using a BZ-9000 microscope (Keyence Co, Osaka, Japan).

\section{RNA extraction}

Total RNA was isolated from the cells by acid guanidinium thiocyanate-phenol-chloroform extraction with Isogen in accordance with the manufacturer's instructions (Nippon Gene Co Ltd, Tokyo, Japan). Cells were homogenized in Isogen $\left(5 \times 10^{6}\right.$ cells $/ \mathrm{ml}$ of Isogen $)$ followed by extraction with $200 \mu 1$ of chloroform. After a second extraction using $650 \mu \mathrm{l}$ of chloroform and precipitation with $1 \mathrm{ml}$ of isopropanol, the precipitated RNA was washed in $1 \mathrm{ml}$ of $70 \%$ ethanol. All centrifugation was done at $12,000 \times g$ at $4^{\circ} \mathrm{C}$. The RNA obtained was dissolved in UltraPure DNase/RNase-free distilled water (Life Technologies, Carsburg, CA, USA), and its concentration was measured by NanoDrop (Thermo Fisher Scientific) at $260 \mathrm{~nm}$.

\section{Quantitative real-time RT-PCR assay}

cDNAs were synthesized from total RNA using a High Capacity cDNA Reverse Transcription kit (Applied Biosystems, Foster City, CA, USA) in accordance with the manufacturer's instructions. As a

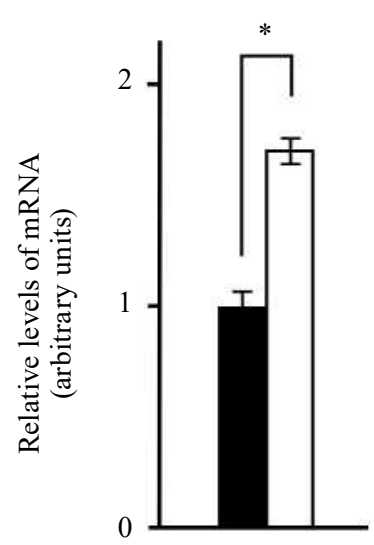

Ins 1

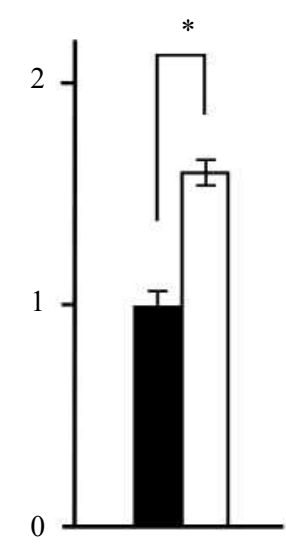

Ins 2
Figure 2. Induction of Ins 1 and Ins 2 mRNA by $m i R-183$ inhibition Quantitative real-time RT-PCR analyses of Ins 1 and Ins 2 relative expression levels. Closed and open bars represent the levels 72 hours after mock (Cy3 anti-miR negative controls) and $m i R-183$ inhibitor transfection, respectively. The relative mRNA expression levels are presented as fold changes after transfection of mock and $m i R-183$ inhibitor, and represent the mean values of four independent assays for each sample. The values were calculated using the Relative Quantity (RQ) Study Software and show the statistical variability in the calculations of each sample's RQ value. The RQmin/RQmax values are graphically represented as error bars. The asterisks denote statistically significant differences $(p<0.05)$.

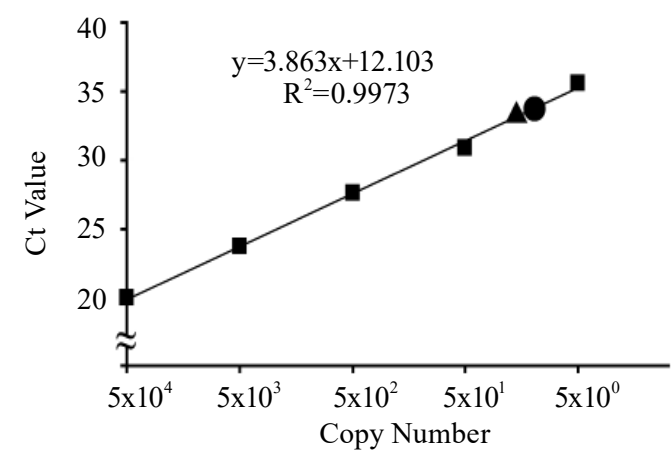

Figure 3 . Scatter plot and standard curve by $\lambda$ polyA + RNA-A $\mathrm{Ct}$ values (represented by squares) are plotted for $\lambda$ polyA+ RNA-A serial dilution samples. $\mathrm{Ct}$ values are plotted for $\lambda$ polyA+ RNA-A serial dilution samples. The $\mathrm{x}$-axis represents the copy number, and the $\mathrm{y}$-axis represents the $\mathrm{Ct}$ value. The standard curve for copy number ranging from $10^{-2}$ to $10^{-6}$ is drawn. Ct values of Insl and Ins2, corrected by an external reference ( $\lambda$ polyA+ RNA-A), were plotted on the standard curve. The circle indicates Insl and the triangle indicates $\operatorname{In} s 2$.

reference to allow comparison between samples, $1.0 \times 10^{8}$ copies of $\lambda$ polyA+ RNA-A (Takara Bio Inc, Kusatsu, Shiga, Japan) were added per $1 \mu \mathrm{g}$ of total RNA during the cDNA synthesis process. Real-time RT-PCR was performed using the Fast SYBR Green PCR Master Mix (Applied Biosystems) to examine the expression levels of each marker. Specific PCR primer sets for Insulin 1 (InsI) and Insulin 2 (Ins 2) were designed using the Perfect Real Time Support System (Takara Bio Inc.). PCR amplification was performed using the StepOne Plus system (Applied Biosystems) with an initial denaturation step of $20 \mathrm{sec}$ at $95^{\circ} \mathrm{C}$, followed by 40 cycles each of $95^{\circ} \mathrm{C}$ for $3 \mathrm{sec}$ and $60^{\circ} \mathrm{C}$ for 30 $\mathrm{sec}$, concluding with an automatic melting curve stage. The expression levels are presented as the fold-change values after induction compared with those before induction and were calculated using the $\Delta \Delta \mathrm{Ct}$ 
$\operatorname{method}^{13)}$. Differences between values were statistically analyzed by the Mann-Whitney U test using SPSS software (https://www.ibm.com/ analytics/us/en/technology/spss/).

\section{Estimation of expressed copy number}

A quantitative standard curve was created using diluted $\lambda$ polyA + RNA-A. Diluted samples $\left(10^{-2}, 10^{-3}, 10^{-4}, 10^{-5}\right.$, and $\left.10^{-6}\right)$ for $5.0 \times 10^{6}$ copies were prepared using the EASY Dilution for Real Time PCR kit (Takara Bio Inc.) and the Real Time primer for $\lambda$ polyA (Takara Bio Inc.) was used for quantitative real-time RT-PCR.

\section{Results}

Detection of insulin in dental pulp cells by inhibition of miR-183

Insulin production was not observed at 72 hours after mock transfection with $\mathrm{Cy} 3$ anti-miR negative controls (Fig. 1A). In contrast, insulin production was observed 72 hours after transfection of the miR183 inhibitor (Fig. 1B).

\section{Induction of insulin mRNA expression by inhibition of miR-183}

Ectopic expression of miR-183 inhibitor induces insulin at 72 hours after induction. Ins 2 is the murine homologue of the human insulin gene and is located on mouse chromosome 7. Ins1, which is thought to have evolved by a gene duplication event, lacks the second intron of the Ins 2 gene, is located on mouse chromosome 19. Qualitative expression analysis showed that Ins 1 and Ins 2 expression significantly increased after miR-183 inhibition by 1.7-fold and 1.6-fold, respectively, ( $p<$ 0.05) (Fig. 2).

\section{Ins1 and Ins2 copy number induced by inhibition of miR-183}

The $\mathrm{Ct}$ mean value was dependent on the serial dilution of $\lambda$ polyA+ RNA-A. The $10^{-2}, 10^{-3}, 10^{-4}, 10^{-5}$, and $10^{-6}$ diluted samples for $1.0 \times 10^{8}$ copies demonstrated $\mathrm{Ct}$ value means of 20.0, 23.7, 27.6, 31.1, and 35.5, respectively. The standard curve was drawn with direct proportional relations $(y=3.863 \mathrm{x}+12.103)$ for a copy number range of $10^{-2}$ to $10^{-6}$ (Fig. 3). $\lambda$ polyA+ RNA-A was added as an external reference during the reverse transcription process. The $\mathrm{Ct}$ value means of Ins 1 and Ins2 were 33.7 and 33.3, respectively, and were plotted on the standard curve. Using the standard curve, the copy number estimates for Ins 1 and Ins 2 were 12.9 and 16.2 , respectively; thus, slightly more than 10 copies were present after $m i R-183$ inhibition.

\section{Discussion}

Highly efficient miRNA-mediated reprogramming of somatic cells has previously been reported ${ }^{14,15}$. The expression of the miR302b/367 or $m i R 302 / m i R-372$ cluster rapidly and efficiently reprograms somatic cells to iPS cells without exogenous transcription factors such as Oct $3 / 4$ or Sox2. Therefore, we hypothesized that cells derived from the dental pulp can be regulated by miRNAs through the process of direct reprogramming. Previously, we comprehensively analyzed changes in miRNA levels during the direct conversion of dental pulp cells into insulin-producing cells by LNA array and reported eight candidate regulatory miRNAs. Notably, 10 days after induction by ectopic expression of the defined transcription factors, $m i R-183$ levels were less than $40 \%$ of those observed pre-induction ${ }^{9}$. To further evaluate the role of miRNAs during this process in dental pulp cells, we inhibited $m i R$ 183 in the cells. We found that inhibition of miR-183 induced insulin expression in dental pulp cells, while no change was observed in mocktransfected cells. These results suggest that the direct conversion of dental pulp cells into the cells of developmentally unrelated tissues involves miRNA-dependent regulation. Recently, some reports show that $m i R-183$ is detectable in human serum, urine, and in exosome vesicles from human sera and is involved in endocrine-associated signal transduction ${ }^{16-18)}$. Given that miRNAs, including $m i R-183$, work as a cluster, it remains unclear whether miR-183 is the only major miRNA involved in this process. Nevertheless, our results show that at least one miRNA, a functional small non-coding RNA, contributes to the direct conversion of cells from one lineage to another. Future directions should focus on elucidating the identity and role of other miRNAs in this process.

The present study has enlarged the potential cell sources suitable for regenerative medicine. Indeed, factors secreted by dental pulp stem cells have been identified to have multifaceted therapeutic benefits for recovery after several types of injuries or diseases, such as those of the spinal cord, heart, and liver ${ }^{19-21)}$. Therefore, pluripotent cells derived from oral tissue are an attractive and promising tool in the field of tissue regeneration and engineering. This study demonstrated that more than approximately 10 copies of insulin mRNA were involved in inducing dental pulp cells. We believe that dental pulp cells, or factors secreted by dental pulp cells, will become an acceptable source of cells for cell therapy in the future, replacing the more controversial sources currently used.

\section{Acknowledgements}

We thank Dr. Mitsuko Masutani for her critical review of the original manuscript and for her helpful insights. We especially thank Dr. Atsushi Shibata for his informative advice related to the revision of the manuscript. This study was supported, in part, by a Grant-inAid for Scientific Research $(21592547,24593020,15 \mathrm{~K} 11283)$ from the Japan Society for the Promotion of Science (T. Nozaki). This study was performed, in part, at the Institute of Dental Research, Osaka Dental University.

\section{Conflict of Interest}

The authors declare that there is no conflict of interest.

\section{References}

1. Nozaki T, Takeyasu M, Hirao A, Shinohara M, Daito M and Ohura K. Differentiation of rat dental pulp-derived cells into an osteoblastic lineage. Oral Sci Int 2: 118-125, 2005

2. Takeyasu M, Nozaki T, Watanabe M, Shinhara M, Morita J, Hikada A, Iwamoto K, Takahashi T, Nagata S, Daito M and Ohura K. In vitro osteogenic differentiation potential of dental pulp stem cells. J Oral Tissue Engin 2: 25-30, 2004

3. Takeyasu M, Nozaki T and Daito M. Differentiation of dental pulp stem cells into a neural lineage. Pediat Dent J 16: 154-162, 2006

4. Nakatsuka R, Nozaki T, Uemura Y, Matsuoka Y, Sasaki Y, Shinohara M, Ohura K and Sonoda Y. 5-Aza-2'-deoxycytidine treatment induces skeletal myogenic differentiation of mouse dental pulp stem cells. Arch Oral Biol 55: 350-357, 2010

5. Nozaki $\mathrm{T}$ and Ohura K. Gene expression profile of dental pulp cells during differentiation into an adipocyte lineage. J Pharmacol Sci 115: 354-363, 2011

6. Mitsui K, Tokuzawa Y, Itoh H, Segawa K, Murakami M, Takahashi $\mathrm{K}$, Maruyama M, Maeda M and Yamanaka S. The homeoprotein Nanog is required for maintenance of pluripotency in mouse epiblast and ES cells. Cell 113: 631-642, 2003

7. Chambers I, Colby D, Robertson M, Nichols J, Lee S, Tweedie $\mathrm{S}$ and Smith A. Functional expression cloning of Nanog, a pluripotency sustaining factor in embryonic stem cells. Cell 113: 643-655, 2003

8. Takahashi K and Yamanaka S. Induction of pluripotent stem cells 
J.Hard Tissue Biology Vol. 26(4):319-322, 2017

from mouse embryonic and adult fibroblast cultures by defined factors. Cell 126: 663-676, 2006

9. Nozaki $\mathrm{T}$ and Ohura K. Regulation of miRNA during direct reprogramming of dental pulp cells to insulin-producing cells. Biochem Biophys Res Commun 444: 195-198, 2014

10. Kahn A. Converting hepatocytes to beta-cells - a new approach for diabetes? Nat Med 6: 505-506, 2000

11. Deutsch G, Jung J, Zheng M, Lóra J and Zaret KS. A bipotential precursor population for pancreas and liver within the embryonic endoderm. Development 128: 871-881, 2001

12. Gu G, Dubauskaite J and Melton DA. Direct evidence for the pancreatic lineage: NGN3+ cells are islet progenitors and are distinct from duct progenitors. Development 129: 2447-2457, 2002

13. Livak KJ and Schmittgen TD. Analysis of relative gene expression data using real-time quantitative PCR and the 2(-Delta C (T)) method. Methods 25: 402-408, 2001

14. Anokye-Danso F, Trivedi CM, Juhr D, Gupta M, Cui Z, Tian Y, Zhang Y, Yang W, Gruber PJ, Epstein JA and Morrisey EE. Highly efficient miRNA-mediated reprogramming of mouse and human somatic cells to pluripotency. Cell Stem Cell 8: 376-388, 2011

15. Subramanyam D, Lamouille S, Judson RL, Liu JY, Bucay N, Derynck R and Blelloch R. Multiple targets of miR-302 and miR372 promote reprogramming of human fibroblasts to induced pluripotent stem cells. Nat Biotechnol 29: 443-448, 2011

16. Motiño O, Francés DE, Mayoral R, Castro-Sánchez L, Fernández-
Velasco M, Boscá L, García-Monzón C, Brea R, Casado M, Agra N and Martín-Sanz P.Regulation of microRNA 183 by cyclooxygenase 2 in liver is dead-box helicase p68 (DDX5) dependent: Role in insulin signaling. Mol Cell Biol 35: 2554-2567, 2015

17. Dioni L, Sucato S, Motta V, Iodice S, Angelici L, Favero C, Cavalleri T, Vigna L, Albetti B, Fustinoni S, Bertazzi P, Pesatori $\mathrm{A}$ and Bollati $\mathrm{V}$. Urinary chromium is associated with changes in leukocyte miRNA expression in obese subjects. Eur J Clin Nutr 71: 142-148, 2017

18. Lima CR, Gomes CC and Santos MF. Role of microRNAs in endocrine cancer metastasis. Mol Cell Endocrinol 2017: doi: 10.1016/j.mce.2017.03.015

19. Yamamoto A, Sakai K, Matsubara, Kano F and Ueda M. Multifaceted neuro-regenerative activities of human dental pulp stem cells for functional recovery after spinal cord injury. Neurosci Res 78: 16-20, 2014

20. Yamaguchi S, Shibata R, Yamamoto N, Nishikawa M, Hibi H, Tanigawa T, Ueda M, Murohara T and Yamamoto A. Detal-pulpderived stem cell conditioned medium reduces cardiac injury following ischemia-reperfusion. Sci Rep 5: 19295, 2015

21. Hirata M, Ishigami M, Matsushita Y, Ito T, Hattori H, Hibi H, Goto $\mathrm{H}$, Ueda $\mathrm{M}$ and Yamamoto A. Multifaceted therapeutic benefits of factors derived from dental pulp stem cells for mouse liver fibrosis. Stem Cells Transl Med 5: 1416-1424, 2016 